The Tang Center for Early China at Columbia University was founded in 2015 through a generous endowment gift from Oscar Tang and Agnes Hsu-Tang. The Tang Center is dedicated to the advancement of the understanding of the richness and importance of early Chinese civilization as a part of a broader common human heritage. It is committed to doing so through both solid scholarship and broad public outreach. The Tang Center sponsors a variety of conferences, workshops as well as public lectures each year including the Columbia Early China Seminar. The Tang Center is especially interested in supporting research initiatives that aim to examine newly discovered paleographic and textual material as well as artifacts, and in promoting the role of archaeology as a path to understand the past.

\title{
Call for Applications
}

The Tang Post-Doctoral Research Award in Early China Studies

The Tang Center for Early China offers one Post-Doctoral Research Award in the amount of $\$ 15,000$ each year in recognition of outstanding research projects in early Chinese civilization or in archaeology.

\section{The Tang Visiting Scholar's Fellowship}

The Tang Center offers Visiting Scholar's Fellowship each year to one scholar for an in-residence research period of 10 months at Columbia University, or to two scholars for a period of 5 months each, depending on the need of the proposed projects. The applicant must be non-US based.

\section{Workshop and Conference Grants}

The Tang Center offers grants in the amount of $\$ 13,000$ each to up to two workshop and/or conference proposals each academic year, depending on the scale. Each workshop or conference should have an identified central problem or theme on which the papers will focus. Alternatively, the workshop/conference can be centered on a newly discovered corpus of materials or manuscripts, or on an important archaeological site, or a region.

Application deadline, November 30, for all programs.

For more information, please visit our website www.tangcenter-columbia.org. Questions directed to: info@tangcenter-columbia.org; or by phone: 212.854.5546.

509 Kent Hall, MC3907, 1140 Amsterdam Avenue, New York, NY 10027 


\section{JOURNAL OF EAST ASIAN STUDIES}

Contents

VOLUME 19 · ISSUE $2 \cdot$ JULY 2019

\section{Articles}

141 When It Rains, It Pours: Foreign Direct Investment and Provincial Corruption in Vietnam

Yong Kyun Kim

169 The Rise of the Princelings in China: Career Advantages and Collective Elite Reproduction

Tony Huiquan Zhang

197 Is Class Voting Emergent in Korea?

Yoonkyung Lee and Jong-sung You

215 Reputation and Compliance with International Human Rights Law:

Experimental Evidence from the US and South Korea

Matthew Dale Kim

239 Policy and Practice in ODA Disbursements: An Analysis of Changes in South Korea's Official Development Assistance

Dennis Patterson and Jangsup Choi

265 Book Reviews 